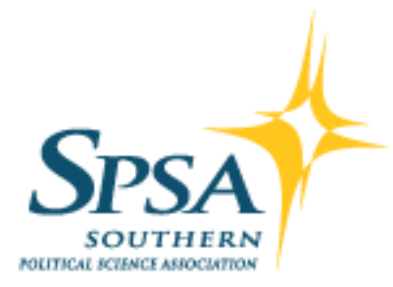

The Polarization of American Politics

Author(s): Keith T. Poole and Howard Rosenthal

Source: The Journal of Politics, Vol. 46, No. 4 (Nov., 1984), pp. 1061-1079

Published by: The University of Chicago Press on behalf of the Southern Political Science Association

Stable URL: http://www.jstor.org/stable/2131242

Accessed: 22-09-2017 21:08 UTC

JSTOR is a not-for-profit service that helps scholars, researchers, and students discover, use, and build upon a wide range of content in a trusted digital archive. We use information technology and tools to increase productivity and facilitate new forms of scholarship. For more information about JSTOR, please contact support@jstor.org.

Your use of the JSTOR archive indicates your acceptance of the Terms \& Conditions of Use, available at http://about.jstor.org/terms

Southern Political Science Association, The University of Chicago Press are collaborating with JSTOR to digitize, preserve and extend access to The Journal of Politics 


\title{
The \\ Polarization \\ of \\ American Politics
}

\author{
Keith T. Poole \\ Carnegie-Mellon University
}

\author{
Howard Rosenthal \\ Carnegie-Mellon University
}

Elected officials in the United States appear to represent relatively extreme support coalitions rather than the interests of middle-of-the-road voters. This contention is supported by analysis of variance of liberal-conservative positions in the United States Senate from 1959 to 1980. Within both the Democratic and the Republican parties, there is considerable variation in liberal-conservative positions, but two senators from the same state and party tend to be very similar. In contrast, senators from the same state but from different parties are highly dissimilar, suggesting that each party represents an extreme support coalition in the state. Moreover, the distribution of senators is now consistent with the hypothesis that, in the long run, both parties have an equal chance of winning any seat in the Senate. This result suggests that there is now competition between equally balanced but extreme support coalitions throughout most of the United States.

W

contend that, at nearly every level of the political system, American politics has been polarized in ways that do not well represent the interests of middle-of-the-road voters. For better or for worse, constituencies are generally fought over by two opposing coalitions, liberal and conservative, each with relatively extreme views. The middle-ofthe-road voter is thus not a member of a silent majority desiring some radical social change, but a moderate individual seeking to avoid the wide swings in policy engendered by our political system. In the environmen-

* This work was supported by NSF grant SES-831-390. The research was performed while Rosenthal was a Sherman Fairchild Distinguished Scholar at the California Institute of Technology. We thank C. Bullock, B. Cain, J. Ferejohn, M. Fiorina, R. Kiewiet, A. Meltzer, and T. Romer for comments, although our own coordinates may not match some of their ideal points. 
tal area, for example, we presume that the middle-of-the-road voter would like to see the EPA strike a more constant posture, somewhere between its relatively zealous pre-Reagan activities and its relatively lax actions in the current administration. Similarly, we suspect most citizens would prefer a federal education policy somewhere between the near total support for NEA positions found in the Carter years and the near total abandonment of a federal role under Reagan.

The aim of this paper is to document that both the composition of the two-member state delegations in the U.S. Senate and the roll-call voting behavior of these delegations have become increasingly consistent with a model of polarized but competitive politics. Specifically, we posit that, in each state, there is evenly balanced competition between polarized groups. Identifying the composition of these groups and relating the composition to constituency characteristics are beyond the scope of this paper (see n. 4).

We begin by asking how we can tell whether middle-of-the-road constituency interests are being represented. A traditional approach has been to assemble a battery of such socioeconomic measures as income, education, and race to determine if roll-call voting is related to constituency variables. This method has several drawbacks, including the difficult problem of accurately measuring a constituency's economic selfinterest on a given issue. ${ }^{1}$

A more direct approach takes advantage of an implication in the notion that legislators represent the particular interests of their constituencies. If middle-of-the-road interests are consistently represented, then legislators from the same constituency ought to be similar ideologically and ought to vote alike.

The U.S. Senate is a terrain de choix for applying this direct method since each state is represented by two senators. There appears to be a very simple method for assessing whether two senators represent a common interest: take all the roll-call votes for a given session of the Senate and compute the percentage of votes for which the pair did not vote alike. If a common constituency interest is being represented, presumably the two senators will almost never vote differently. They certainly should have less disagreement with each other than they have with other members of the Senate.

Unfortunately, looking at disagreement percentages is a flawed approach. Consider two states, the first with a very liberal senator and a moderately liberal senator, the second with a moderately conservative

${ }^{1}$ For a detailed review of this literature, see Fiorina (1974). See also Kuklinski (1979) and the recent critique by Peltzman (1982). 
senator and a very conservative senator. Next, consider a series of votes on, say, voting rights, that divide moderate conservatives from more extreme ones. In this case, the two senators from the first state will vote together while the two from the second state will split. While each pair of senators has the same ideological separation, one pair agreed and the other did not. This situation illustrates how the disagreement percentage depends not only on intrinsic differences between the senators but also on the content of the bills before a given session of the Senate. ${ }^{2}$

To find this intrinsic policy difference or distance between two senators, we instead start with direct measures of distances. Each year, some thirty interest groups in Washington, including COPE, ACU, ADA, and UAW, rate senators. The ratings offer a measure of the distance between each interest group and the senator: a high rating is low distance, and a low rating is high distance. By employing the technique of least squares unfolding (Poole, 1984), we can use these distances to place both the interest groups and the senators on a liberal-conservative scale. We have scaled all twenty-two sessions of Congress from 1959 through 1980 using this method. Scale values for the senators generally range from near -1 for extreme liberals (such as Ted Kennedy) to +1 for extreme conservatives (such as Jesse Helms). The liberal-conservative placements accurately reproduce the original ratings. ${ }^{3}$

We have reason to believe that our procedure is very robust. For 1979 and 1980, we employed an entirely different scaling procedure, one based solely on the recorded roll-call vote data (Poole and Rosenthal, 1985). This procedure, which uses all roll calls rather than just those selected by interest groups, recovered liberal-conservative locations for the senators virtually identical to those obtained from the interest-group ratings. In addition, we recovered similar liberal-conservative positions when we used a much cruder least squares decomposition (Poole, 1983) of the rollcall votes. The common scale recovered by these techniques correctly classifies upwards of 80 percent of the individual votes in the Senate. It is as successful on votes not used by the interest groups as it is on the votes used for the ratings (Poole and Daniels, 1985). We thus conclude that we are accurately capturing liberal-conservative positions in the Senate and that these positions represent the major and dominant factor underlying roll-call voting behavior.

By discarding disagreement percentages and favoring liberal-conservative positions, we maintain the basic comparative technique. For middle-of-the-road representation, it is necessary (but not sufficient) that

\footnotetext{
2 For a formal discussion of this point, see Morrison (1972).

${ }^{3}$ For a detailed description of the scaling, see Poole $(1981,1984)$.
} 
senators from the same state be close to each other on the liberal-conservative scale. ${ }^{4}$

The middle-of-the-road proposition is most likely to be challenged when one senator is a Democrat and the other is a Republican. From 1977 through 1982, California was represented by Alan Cranston, a very liberal senator, and Sam Hayakawa, a very conservative one. This ideological separation is not unusual for California: Hayakawa's seat had previously been held by Tunney, a liberal, and Tunney was preceded by the very conservative Murphy. Before Tunney, a six-year term was served by the liberals Engle and Salinger. They were preceded by an archconservative, William Knowland. The California example is obviously very damaging to the case of middle-of-the-road democracy. But is California typical of the entire nation?

To study this question, we began by dividing the states into three types as shown in figure 1. There are states with two Republican senators, states with two Democrats, and states with a mixed delegation. ${ }^{5}$ The number of mixed states has steadily risen. While half the increase reflects the collapse of the solid South, mixed delegations increased throughout the nation. By 1980 , half the states were mixed.

The distribution of states between mixed and solid types depends on the nature of competition. One possible model is that of national competi-

4 Related research on the House, to be discussed later, is found in Fiorina (1974). Subsequent to the initial draft of this paper, we discovered the work of Bullock and Brady (1983), who used a methodology almost identical to ours with similar results. There are several differences between our work and theirs: (1) we treat twenty-two years rather than a single year; (2) rather than using just two rating scales per year, we use a synthesis of over fifty scales. Since the recovered positions "explain" all votes to about the same degree (Poole, 1981; Poole and Rosenthal, 1985; Poole, 1984), we can now claim that the Fiorina and Bullock-Brady type of results are robust to the scales chosen for analysis. (3) We preserve a distinction between homogeneous Democratic states and homogeneous Republican states. This distinction proves relevant in the analysis. On the other hand, Bullock and Brady's paper is more ambitious than ours in the sense that they attempt to explicate these findings in terms of the heterogeneity of states. A similar comparison of pairs of senators from the same state is found in Peltzman (1982).

5 The number of cases in each type is obviously small. Consequently, readers are urged to look at the trends over several years presented in the figures and not to focus on results for individual years. In developing the types, we made the following decisions. Strom Thurmond switched from Democrat to Republican in 1964. We classified him as a Democrat prior to 1964, as a Republican after 1964, and we discarded South Carolina from the analysis in 1964, which explains the presence of only forty-nine states in that year. In addition, Harry Byrd, Jr. of Virginia left the Democrats in 1970 to become an independent. Virginia has been discarded from the analysis for 1970 through 1980 . It was also necessary to discard South Dakota (except for figure 1) in 1972 because Karl Mundt had no recorded votes for that year. Had Mundt voted, our results would have been reinforced since South Dakota's other senator was the highly liberal George McGovern. 
Figure 1

Number of States of EAch Type

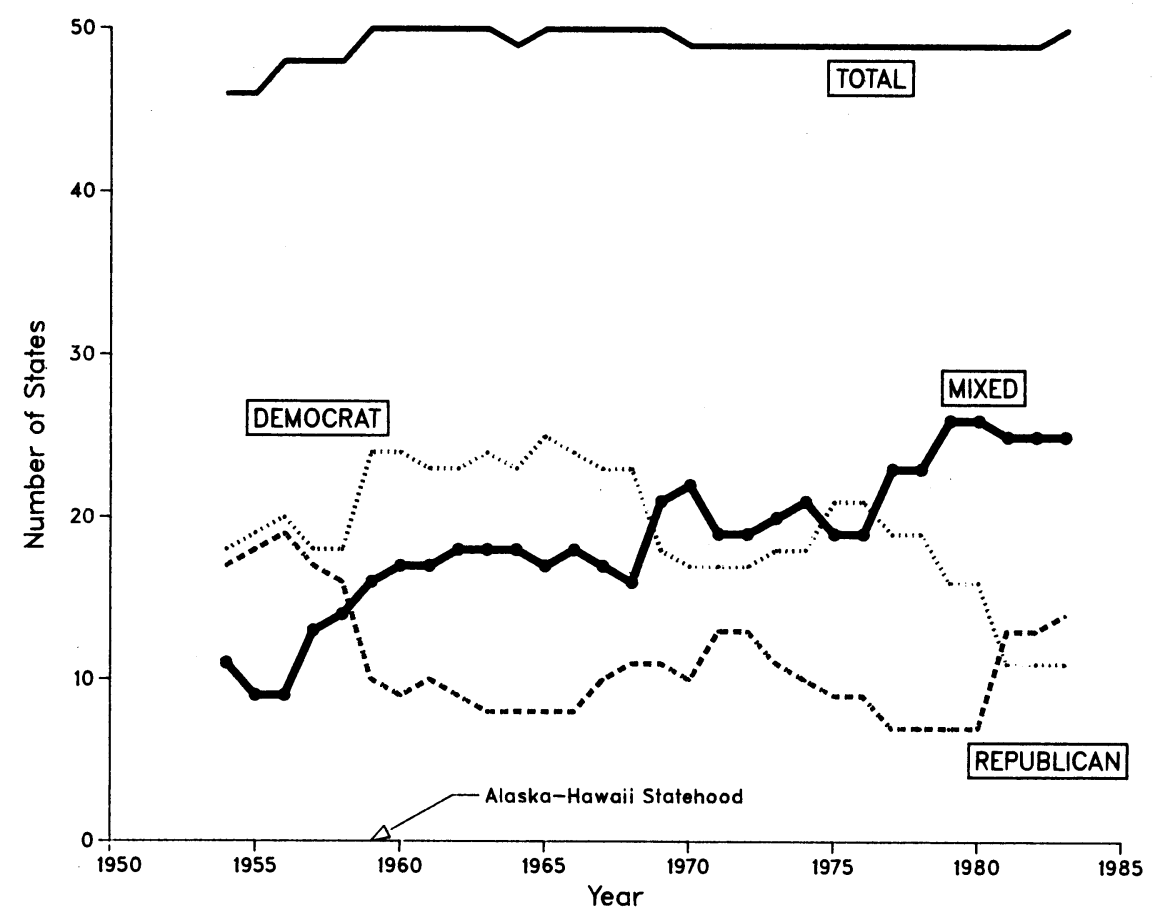

tion. For example, one party-the Democrats-might represent the poor, those with below the national median income, and the other party represents the rich. In such a situation, one would expect to find relatively few mixed states; poor states would be solid for the Democrats and rich ones solid for the Republicans. An alternative view is a model of local competition, which corresponds to the view that national parties are actually coalitions of local parties (see Sundquist, 1973, p. 37). In the stylized local model, the Democrats would, in each state, represent those with below median state income.

Under local competition, with party coalitions evenly balanced in each state, we would have a fully competitive Senate. This model leads to a strong prediction about the distribution of mixed and solid delegations. Under this model, the long-run probability that any seat is won by either of the two parties would be one-half. (We say "long run" because we do not want to rule out scandal, incumbency, and other factors giving a short-run bias to one party.) When full competition prevails, one ex- 
pects on average, 50 percent of the states to be represented by mixed delegations, 25 percent to have homogeneous Republican delegations, and 25 percent to have homogeneous Democrat delegations. ${ }^{6}$ Historically, the composition of the Senate is not consistent with this competitive model. Examination of the data for the period 1912-1959 discloses that mixed delegations were always far less than 50 percent of the total. At the beginning of our liberal-conservative time series, in 1959, with the Democrats in control, there were still only sixteen mixed delegations, and there was less than one chance in one thousand that the observed distribution would arise under the null hypothesis of full competition. But after 1980 , when the distribution is very close to the expected $50-25-25$, the chances become better than nine in ten. The current distribution of delegations is consistent with our claim of intense competition between opposing ideological coalitions.

Our aim is to assess the ideological similarity of senators from a given state. To do this, we must know something about the variability in positions of all senators. This variability can be captured in the measure of variance in liberal-conservative positions. ${ }^{7}$

One cannot formally compare variances from separate scalings. Moreover, the substantive nature of the bills and issues that fall along the liberal-conservative dimension changes from year to year. Perhaps the basic content of "liberal" and "conservative" also changes. Such changes are not central to our analysis, which is concerned with whether polarization occurs on issues that are currently relevant. To place the scaling in a common frame of reference appropriate for our purposes, we first carried out a linear transformation of each scale. ${ }^{8}$

The transformations and the liberal-conservative coordinates for a combined scale were chosen to minimize the sum of squared errors between the combined scale and the original scales. This technique assumes that the liberal-conservative positions of individual senators are stable in time. Thus, variations in the liberal-conservative makeup of the Senate would arise mainly through changes in membership (Bullock, 1981; Stone, 1977, cited by Kuklinski, 1979; and Clausen, 1973). The results of the combined scale are consistent with this view of stability. The

6 This point is ignored by Bullock and Brady (1983), who use the presence of a mixed delegation in a state as a measure of competitiveness in their path analysis. But such a measure is biased since, in a fully competitive world, one-party delegations will arise as frequently as mixed ones. A Senate with all delegations mixed would not be consistent with competition but with some other model, such as duopolistic sharing of seats.

${ }^{7}$ See the Appendix for details on the variance computations.

${ }^{8}$ We used the procedure of Poole (1983), which generalizes the Eckart-Young (1936) matrix approximation method to allow for missing data. 
combined scale correlates very highly with each of the yearly scales. ${ }^{9}$ The results below are based on the transformed yearly scales.

The variance for the entire Senate is plotted in figure 2. The variance exhibits no long-term trends. There is a slight dip during the Great Society and peaks during Vietnam and Watergate, but values in the last three years are very close to those of the first three years. Throughout the past two decades, there has been a polarized distribution in the Senate, with liberal and conservative clusters and relatively few moderates in the center. Typical histograms are shown in figure 3 for six of the twentytwo years. The plot of the variance shows that we will be concerned with a basic pattern of representation, one prevalent throughout the period.

Below the plot of the variance, figure 2 also shows the percentage of the variance that is explained by separating the senators into the three types

\section{FigURE 2}

\section{Senate. Variance on Liberal-Conservative Dimension}

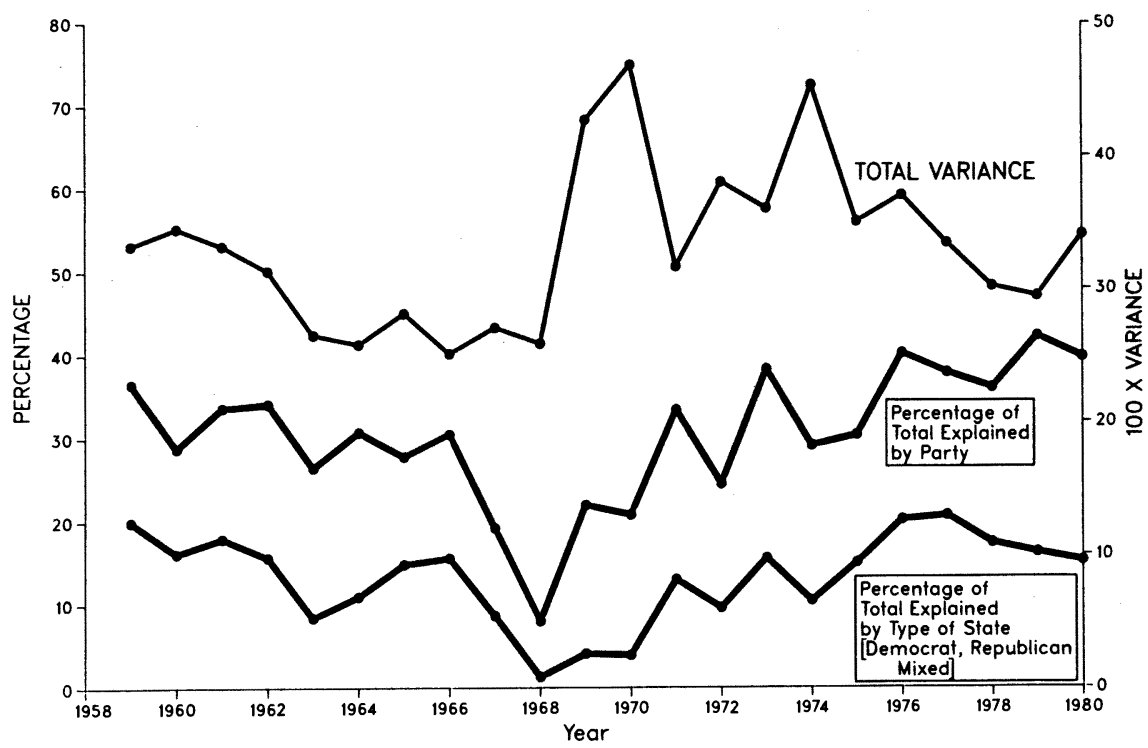

${ }^{9}$ Squared correlations between individual years and the combined scale range from 0.88 to 0.97 . Results reported in this paper are virtually identical to those obtained using the untransformed scales. In fact, the linear transformations show little variation across years. Nonetheless, results such as the variance plot in figure 2 do not follow automatically from this year-to-year stability. Since the correlations are computed for the members of the Senate in a given year, variances could vary across years because of changes in the Senate's membership. 
of states. This series is unit-free, and it has no year-to-year comparison problems. Again, there are no long-term trends, although there is a dip that bottoms out at the height of the Vietnam controversy. The important finding is that the state types account for little of the ideological

\section{Figure 3}

Liberal-Conservative Distribution of U. S. Senate
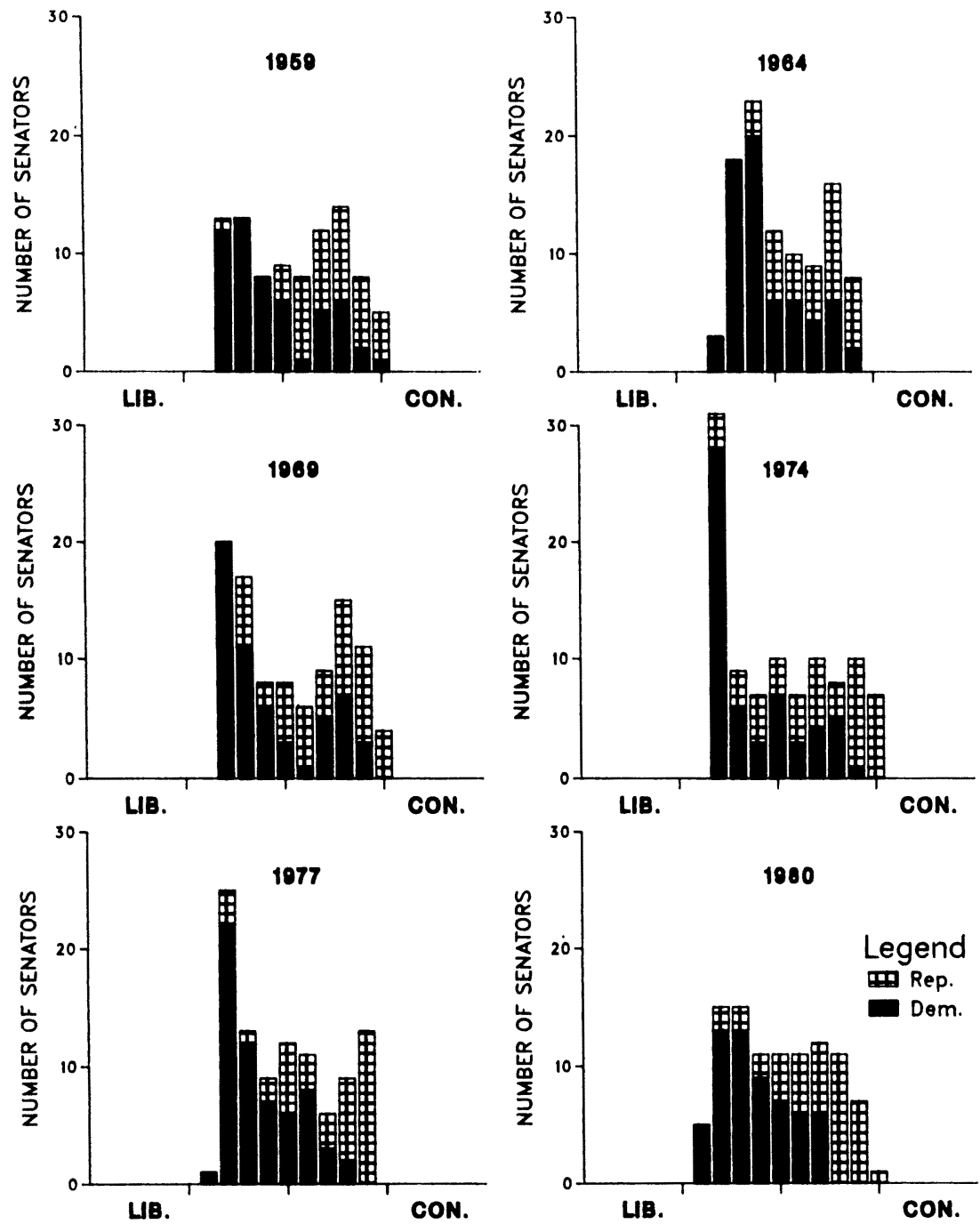
variability in the Senate. The percentage averages about 10; only once does it pass, barely, 20.

One key factor in the small percentage of the variance explained by separating the states according to type is that mixed-state senators do not behave alike; rather, to some degree, they behave like Democrats and Republicans. Indeed, figure 2 shows that if we separate by party instead of by state type we explain more of the variance. It also indicates that party has become more important in recent years (largely because of the lesser weight of southern conservatives among the Democrats). But party itself never explains as much as half the variance. Most of the variability in senatorial liberal-conservative positions cannot be explained by party affiliation; it must instead be explained by variations between and within state delegations.

Comparison of the within-state variation to the between-state variation is the central element in our argument. First, however, we pause to consider the total variation for each type relative to the total variation for the Senate, as plotted in figure 4. If a delegation type was as heterogeneous as the Senate as a whole, its own variance would be 100 percent of the variance of the full Senate. A totally homogeneous type, with all its senators at a single value on the scale, would be at 0 percent.

\section{Figure 4}

Type Variance as a Percentage of Total Variance

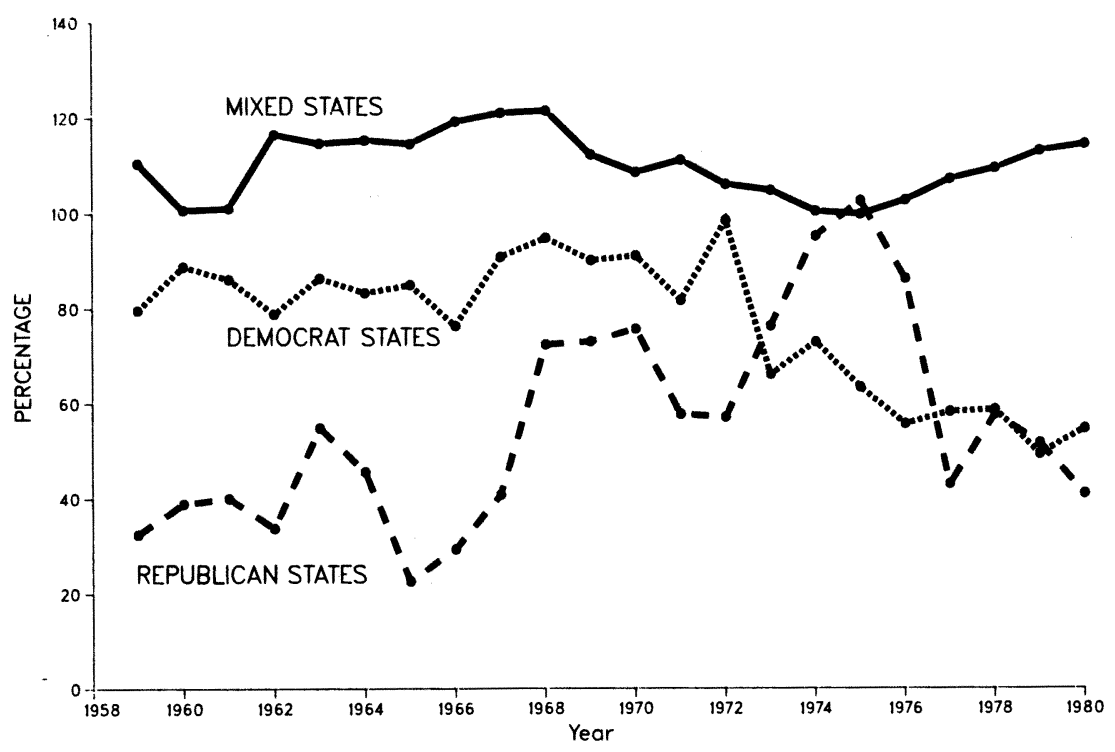


Democratic and Republican states are, as expected, more homogeneous than the Senate as a whole. Undoubtedly because of the presence of southern conservatives, the Democrats were initially not very homogeneous. Until Nixon's second term, their variance was generally between 80 and 100 percent of that of the full Senate. The Republicans were initially more homogeneous, approximately 40 percent of the full Senate. But the senatorial party was badly split during Watergate, and the Republican figure actually exceeded 100 percent in 1974 and 1975. Carter's presidency was needed to reunify the party.

Under Carter, the two parties looked very similar in their degree of heterogeneity, supporting our position on two competitively similar opposing coalitions. Although the Democratic and Republican types were more homogeneous than the full Senate, they still exhibited substantial diversity in liberal-conservative positions, the percentage for both types hovering near 50 percent during the Carter years.

In turn, the mixed delegations are far more heterogeneous than the one-party delegations. Indeed, they tend to be slightly more heterogeneous than the Senate as a whole, since their percentage - which exhibits little temporal variation-oscillates between 100 and 120 percent.

The heterogeneity of mixed delegations need not have occurred. If homogeneous Republican states were "conservative" states, homogeneous Democrat, "liberal," and mixed, "moderate," then the mixed delegations could have been as homogeneous as the one-party delegations. Instead, the heterogeneity of mixed delegations suggests that these states are far from moderate in their representation.

We now turn to the analysis of the heterogeneity in mixed and solid types. The total variance for a type equals the variance within states plus the variance between states. If both senators from a given state represent the same constituency interest, the within-state variance should be quite small. The heterogeneity within a type should be explicable by the varying interests of the states.

The Democratic and Republican types witness consistent interest representation. For the Democrats, within-state variance is perennially extremely small, about 10 percent of the total type variance (see figure 5). For the Republicans, it is only slightly larger, with the exception of two peaks: one in 1965-1966, the other from 1971 through 1976. Even at the peaks, however, within-state variance is always less than between-state variance. One of the peaks is largely explicable. In the 1970 New York senatorial elections, our model of two opposing coalitions broke down. A triangular contest saw the election of James Buckley, a conservative, while New York's other Republican senator, Jacob Javits, remained the 
most liberal Republican member of the Senate. Political observers correctly predicted that Buckley's deviant political behavior would not survive one term. Deleting New York from the analysis for the Buckley years dampens the peak considerably (again, see figure 5). Since Buckley's departure in 1976, the Republican and Democratic types have closely resembled each other.

Summarizing the results for one-party states, we found important and similar residual variation after controlling for party, as shown in figure 4. As demonstrated in figure 5 , this residual variation is overwhelmingly the result of variation across states, and it only slightly reflects variation between senators from the same state. Senate-watchers have in fact suggested to us that senators from the same party and state actively consult each other prior to voting. They are thus likely to represent the views of their support coalitions rather than their personal ideological views.

Are the support coalitions representative of middle-of-the-road citizens? The data for mixed states argue strongly that the Democratic and Republican support coalitions in each state represent relatively extreme views. The two senators from a mixed state do not adopt common positions. The within-state variance percentage in this type always substantially exceeds that for the Republican and Democratic types, and

Figure 5

Percentage of Type Variance that is Within-State

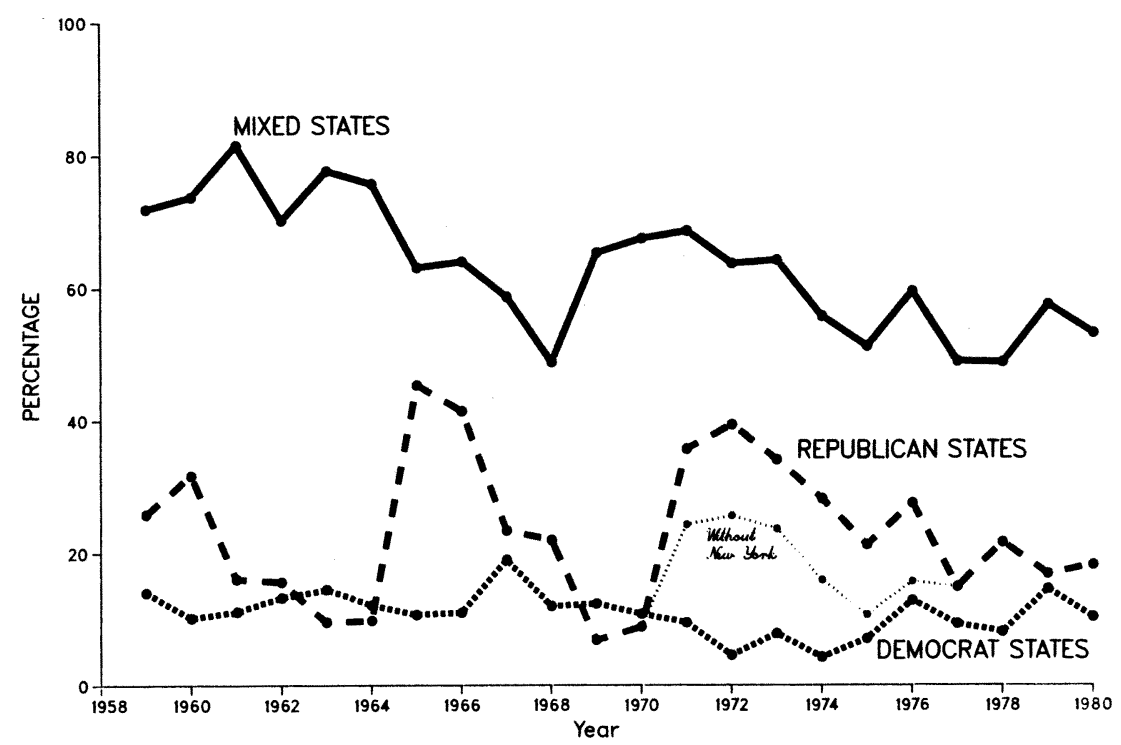


it is generally over 50 percent of the total. That is, there are generally more differences internal to each state than there are between the various states. State interests are thus less important than the support-coalition interests within each state. ${ }^{10}$

The same story is told in slightly different form in figure 6 . There we plot a within-state standard deviation (the square root of the variance) band for each type. That is, each band shows the variation we would expect if all senators for a type both came from an average state for that type and exhibited only within-state variation. Bands for the homogeneous Democratic and Republican types are narrow and generally well separated. They overlap only briefly and slightly for three of the Vietnam years. In contrast, the mixed-state band is very large, usually covering all of the Democratic and much of the Republican band. These results argue strongly that while constituency interests are represented in Congress, the interests are mainly those of relatively extreme support coalitions rather than those of middle-of-the-road voters.

Some indication that support-coalition interests may be abating in favor of general constituency interests is found in figure 5 , which shows that the importance of within-state variation in mixed states has

\section{Figure 6}

\section{One Standard Deviation Bands for Within-State Variance}

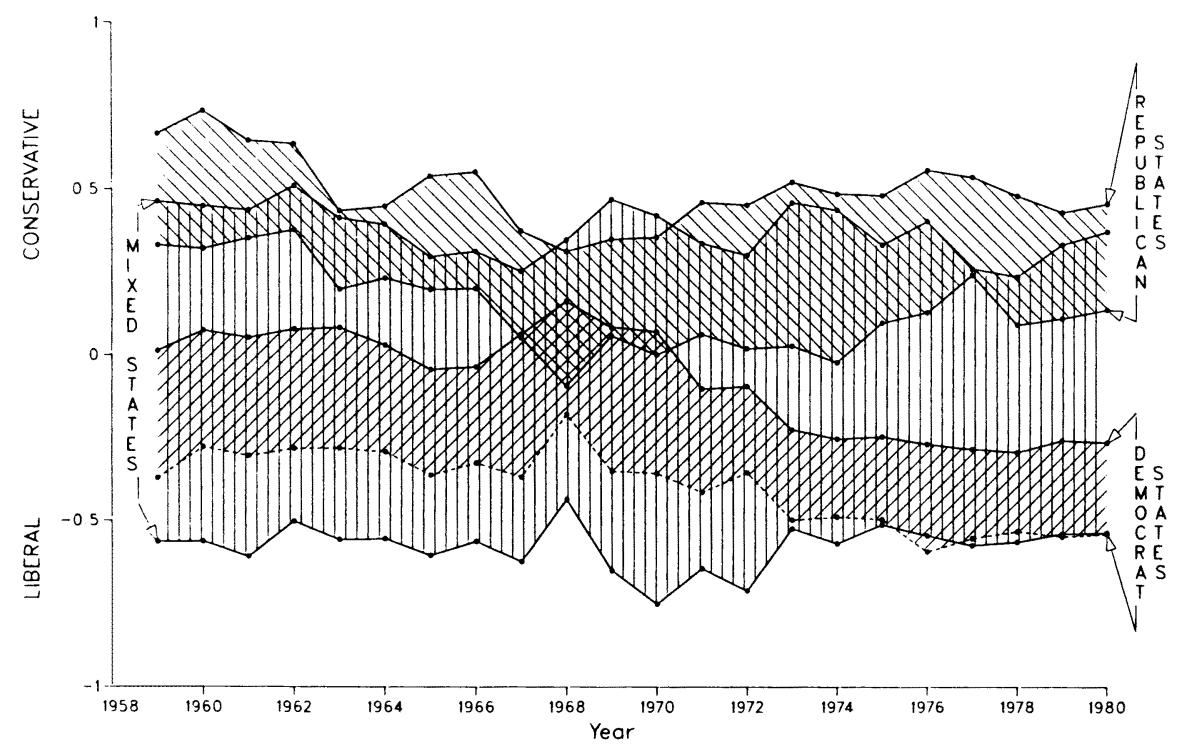

${ }^{10}$ This argument has been made by Huntington (1950), Fiorina (1974), and Fenno (1977). 
undergone a secular decline, falling from the 70-80 percent range found until 1965 to a 50-60 percent range found after 1973. Such a fall would be consistent with the increased emphasis on case work and home-office staffs found in recent years (Fiorina, 1978). Yet the fall is largely offset by another phenomenon, the increasing polarization of the underlying support coalitions. This is seen in figure 7 , where we have plotted standard deviation bands for the total type variance of Republican and Democratic types. A similar story is told by figure 8, where the plots concern all senators and not just those from one-party delegations. PreVietnam party positions were fairly polarized, and there was only moderate overlap of the bands. With Vietnam, party lines became blurred, and a very substantial overlap appeared. Since 1975, however, party separation has been greater than ever, largely occasioned by a secular liberal drift of the Democrats. The overlap is now smaller than it has been since 1959. So, while senators may be slightly less prone to vote their support coalition's interests, those interests are more polarized than ever. ${ }^{11}$

\section{Figure 7}

\section{One Standard Deviation Bands for Total Type Variance}

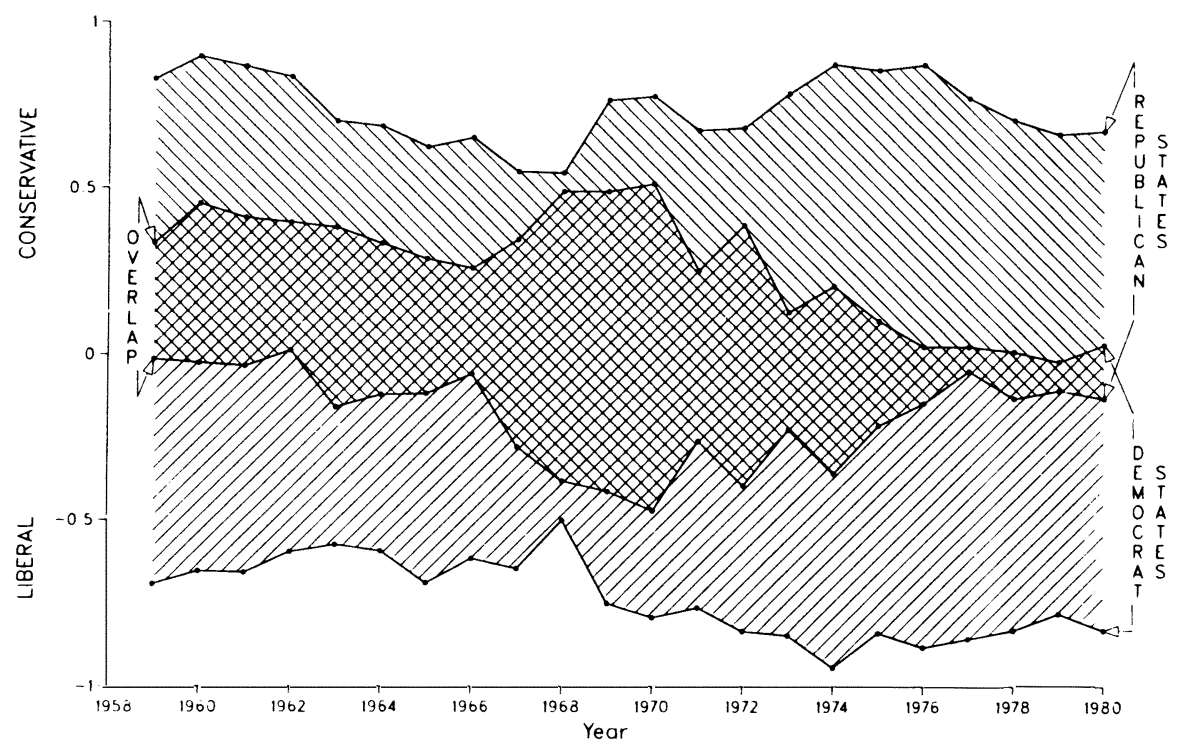

${ }^{11}$ Bullock (1981) indicates that newly elected House southern Democrats are more liberal than Democrats they replace whereas newly elected southern Republicans are more conservative than their predecessors. 


\section{Figure 8}

One Standard Deviation Bands for All Party Members

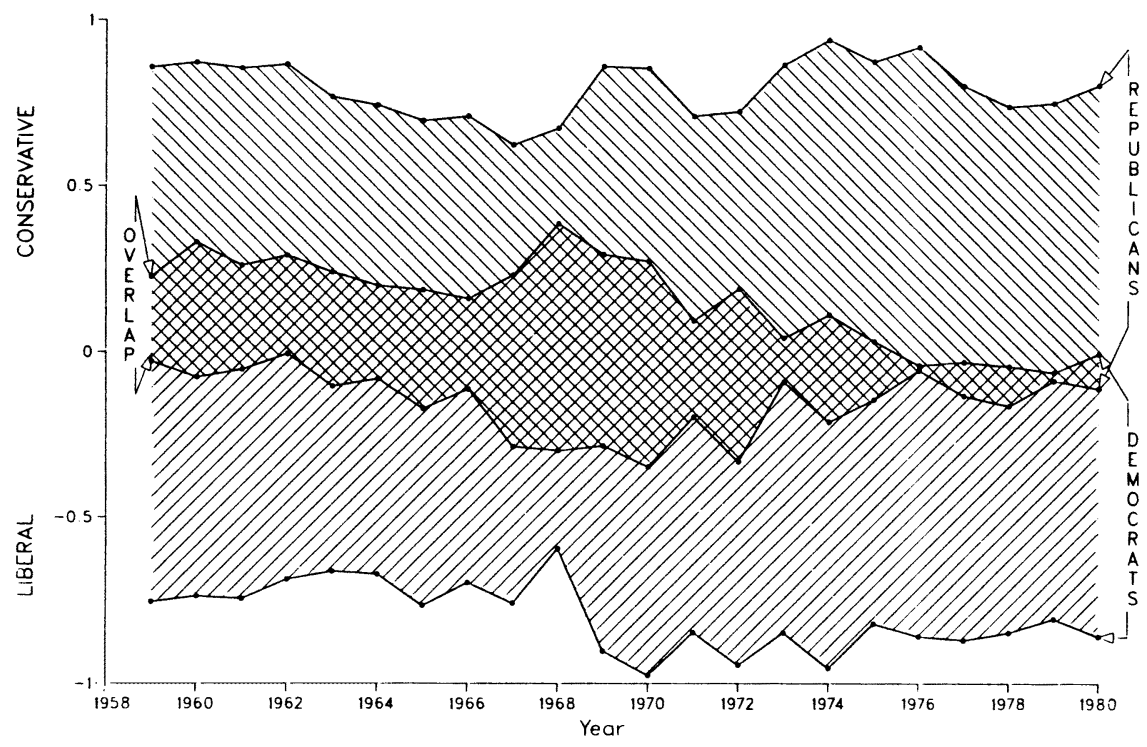

The polarization of the positions of individual senators in terms of their support coalition's interests may have muted policy consequences if liberals and conservatives are balanced in the Senate. However, the scales can tip. Recent work, based on the alternative roll-call method described above, shows that eighteen senators serving in the 95th Congress had replacements in the 96th Congress whose average position was threefourths of a unit more conservative on our two-unit scale. This shift is hardly unrelated to the shift in economic policy brought about by the Reagan administration.

The trend to polarized competition that can sustain substantial shifts in policy is partly the consequence of the disappearance of traditional southern politics (Bullock, 1981). Southern Democratic senators have become less conservative, and southern Republican senators who have broken the solid South are generally very conservative. The development of a two-party South accounts for about half the trend to more mixed states shown in figure 1.

Events outside the South are of equal importance. Moderate Republicans are vanishing nationally. California again provides an ex- 
ample. At the beginning of our time series, the other California Senate seat was held by Thomas Kuchel, a moderate Republican almost at the center of the spectrum. In 1968, Kuchel was replaced by the highly liberal Democrat, Alan Cranston. It is difficult to imagine a moderate from either party having much success in contemporary California politics. Moderate-central positions are generally disappearing in favor of the relatively extreme positions of support coalitions.

Why are general constituency interests so often sacrificed to those of support coalitions? Our interest-group ratings themselves tell much of the story. In our liberal-conservative scaling, most of the interest groups turn out to be more extreme than most of the senators (Poole, 1981). Groups with moderate views do not get involved in politics. Candidates in turn need people willing to contribute money and ring doorbells. While some competitive pressures may push candidates toward the center, the need for resources retains them at the extremes. Ladd $(1982$, p. 66) notes that "college [-educated] Democrats are noticeably more liberal . . . than their party's rank and file, while college [-educated] Republicans are rather consistently more conservative than their party's mass membership." This "polarization of the activist cohorts of the respective parties" means that although candidates might win votes by moving to the center, a centrist position will generally leave them without enough resources for an effective campaign. In particular, a centrist position may spell doom in primary elections (Wright, 1978; Polsby and Wildavsky, 1980).

We indicated at the outset that we expect our analysis to apply far beyond the Senate. The presidential analogue of the story is typified by our EPA and education examples. Wittman (1983) recently surveyed four studies that show "persistent differences" in policies of Democratic and Republican presidents or in positions of Democratic and Republican presidential candidates. Most relevant is the work of Hibbs (1977), who has argued for the presence of an "ideological business cycle" (our term) brought about by shifts in administration. At the state level, we could continue to look at California, appealing to the Brown-Reagan-BrownDeukmejian shuffling in the governor's office. Rather than a continual adjustment of middle-of-the-road policies, there are relatively rapid swings in the policy preferences of elected representatives and executives.

At first glance, the House of Representatives appears to yield somewhat different results. On the one hand, our results are similar to those of Fiorina (1974), who compared changes in a constituency's roll-call behavior when the seat changed parties. Yet the key observation about the House is not that party makes a difference in how the constituency's representative votes, but that so few seats change party. We have a bountiful literature on vanishing marginals, declining competition, and 
the incumbency advantage. ${ }^{12}$ The House seems very different from our fully competitive Senate.

To some degree, it is easier to observe competition in the Senate than in the House. When we talked about the Senate as being fully competitive, we spoke of long-term probabilities. Indeed, incumbency has obvious advantages in the Senate also. A major recession notwithstanding, the Senate's delegation composition barely budged in the 1982 elections. Despite short-term incumbency advantage, Senate seats look more competitive than those of the House, because of the election of two members per constituency. The presence of mixed delegations makes competition manifest. Certainly, if the House had two-member constituencies, we could also expect large numbers of mixed delegations.

However, institutional features make the House less competitive than the Senate. Prolific gerrymandering (Abramowitz, 1983) creates homogeneous House districts (Cain, forthcoming). In homogeneous farming, suburban, or black districts, for example, middle-of-the-road constituency interests are almost trivially represented. In addition, the smaller size of House districts will naturally result in greater social homogeneity and less competition (Hibbing and Brandes, 1983). But instead of a polarization of support groups within constituencies, as in the Senate, the House would then have a polarization of constituencies. Representatives are still likely to exhibit policy preferences that are extreme relative to national averages. In fact, histograms for the House similar to figure 3 indicate that the liberal-conservative distribution in the House is far more polarized than in the Senate (Poole and Daniels, 1985). Since spatial analyses of policy preferences (Rabinowitz, 1978; Poole and Rosenthal, 1985) often disclose a unimodal distribution in the mass public, the polarized distribution of elected representatives and interest groups represents a curious form of representation.

We are sufficiently sophisticated students of social choice to make no normative case for middle-of-the-road representation over supportcoalition representation. Some colleagues have in fact taken the position that polarized representation has a normative value: providing a mechanism for implementing significant policy change. As a counterweight to this view, we note that alternation in power among support coalitions imposes considerable costs. In the last months of the Brown administration in California, the state initiated commuter rail service between Oxnard and Los Angeles. Shortly after Deukmejian took office, the service was abandoned. While it is uncertain whether abandonment was preferable to continuing the service, never starting the service at all would clearly dominate the actual policy sequence. Unfor-

12 As examples of this literature, see Ferejohn (1977) and Fiorina (1978). 
tunately, the costs of ping-ponging may be inevitable in a pluralist democracy. ${ }^{13}$

\section{REFERENCES}

Abramowitz, Alan F. (1983). "Partisan Redistricting and the 1982 Congressional Elections." Journal of Politics 45: 767-70.

Bullock, Charles S., III (1981). "Congressional Voting and Mobilization of a Black Electorate in the South." Journal of Politics 43: 662-82.

Bullock, Charles S., III, and David W. Brady (1983). "Party, Constituency, and Roll Call Voting in the U.S. Senate." Legislative Studies Quarterly 8: $29-43$.

Cain, Bruce E. (forthcoming). The Reapportionment Puzzle. Berkeley: University of California Press.

Clausen, Aage R. (1973). How Congressmen Decide: A Policy Focus. New York: St. Martin's Press.

Eckart, Carl, and Gale Young (1936). "The Approximation of One Matrix by Another of Lower Rank." Psychometrika 2: 211-18.

Fenno, Richard (1977). Home Style. Boston: Little, Brown.

Ferejohn, John (1977). "On the Decline of Competition in Congressional Elections." American Political Science Review 71: 166-76.

Fiorina, Morris P. (1974). Representatives, Roll Calls and Constituencies. Lexington, MA: D. C. Heath.

(1978). Congress: Keystone of the Washington Establishment. New Haven: Yale University Press.

Hibbing, John R., and Sara L. Brandes (1983). "State Population and the Electoral Success of U.S. Senators." American Journal of Political Science 27: 808-19.

Hibbs, Douglas A., Jr. (1977). "Political Parties and Macroeconomic Policy." American Political Science Review 71: 1767-87.

Huntington, Samuel P. (1950). "A Revised Theory of American Party Politics." American Political Science Review 44: 669-77.

Kuklinski, James (1979). "Representative-Constituency Linkage: A Review Article." Legislative Studies Quarterly 4: 121-41.

Ladd, Everett C. (1982). Where Have All the Voters Gone? New York: Norton.

Lijphart, Arend (1977). Democracy in Plural Societies. New Haven: Yale University Press.

Morrison, Richard J. (1972). "A Statistical Model for Legislative Roll Call Analysis." Journal of Mathematical Sociology 2: 235-47.

Peltzman, Sam (1982). "Constituent Interest and Congressional Voting." Mimeo. University of Chicago.

Polsby, Nelson W., and Aaron Wildavsky (1980). Presidential Elections. New York: Scribners.

Poole, Keith T. (1981). "Dimensions of Interest Group Evaluation of the U.S. Senate 1969-1978." American Journal of Political Science 25: 41-57.

${ }^{13}$ Lijphart (1977) has suggested that pluralist two-party systems typified by Britain and the United States may be more subject to wide policy swings than multiparty proportional systems typified by the Netherlands and Switzerland. He gives the nationalization-denationalization cycles of the British steel industry as an example of how ping-ponging may be more costly than a consistent policy. 
(1983). “Recovering a Basic Space From a Set of Issue Scales." Working Paper \#44-82-83. Graduate School of Industrial Administration, Carnegie-Mellon University, Pittsburgh, PA.

(1984). "Least Squares Metric, Unidimensional Unfolding. Psychometrika 49.

Poole, Keith T., and R. Steven Daniels (1985). "Ideology, Party and Voting in the U.S. Congress 1959-1980." American Political Science Review 79. Forthcoming.

Poole, Keith T., and Howard Rosenthal (1985). "A Spatial Model for Legislative Roll Call Analysis." American Journal of Political Science 29. Forthcoming. (1984). "U.S. Presidential Elections 1968-1980: A Spatial Analysis." American Journal of Political Science.

Rabinowitz, George (1978). "On the Nature of Political Issues: Insights From a Spatial Analysis." American Journal of Political Science 22: 793-817.

Stone, Walter J. (1977). “A Panel Analysis of Representation in Congress: A Preliminary Report." Paper presented at the Annual Meeting of the American Political Science Association, Washington, D.C.

Sundquist, James L. (1973). Dynamics of the Party System. Washington, D.C.: Brookings Institution.

Wittman, Donald (1983). “Candidate Motivation: A Synthesis of Alternative Theories." American Political Science Review 77: 142-57.

Wright, Gerald C. (1978). "Issue Structure in Congressional Elections: The Impact of the Primary Electorate." Paper presented at the Annual Meeting of the Midwest Political Science Association, Chicago.

\section{Appendix: Computation of the Variances}

Let $X_{i}$ be the coordinate of Senator $i$. Then, the average coordinate of some subset of senators $S$ of size $N_{s}$ is

$$
\bar{X}_{s}=\sum_{i \in S} X_{i} / N_{s}
$$

and the variance is

$$
\operatorname{Var}(X)_{s}=\sum_{i \in S}\left(X_{i}-\bar{X}_{s}\right)^{2} / N_{s}
$$

Let $X$ and $\operatorname{Var}(X)$ be the average and variance respectively for the entire Senate. Then the between-party variance is

$$
V_{B}=\frac{N_{D}\left(\bar{X}_{D}-\bar{X}\right)^{2}+N_{R}\left(\bar{X}_{R}-\bar{X}\right)^{2}}{N_{D}+N_{R}},
$$

where $D$ denotes the subset of Democrats, $R$, Republicans. Then the percentage explained by party (fig. 2 ) is 


$$
P E=100 \frac{V_{B}}{\operatorname{Var}(X)} .
$$

The percentage explained by state type is computed in a similar fashion.

Computation of the percentages in figure 4 can be illustrated by the Democrats:

$$
P D_{H}=100 \frac{\operatorname{Var}(X)_{D_{H}}}{\operatorname{Var}(X)},
$$

where $D_{H}$ refers to Democratic senators from homogeneous states with two Democratic senators.

The between-state variance for the Democratic type is computed as follows. Let $X$, be the average of the position of the two senators from the state $j$. Then,

$$
V_{B D_{H}}=\underset{j \in D_{H}}{\Sigma}\left(X_{j}-\bar{X}_{D_{H}}\right)^{2} /\left(N_{D_{H}} / 2\right) .
$$

The within-state variance can then be found by using a well-known identity.

$$
V_{W D_{H}}=\operatorname{Var}(X)_{D_{H}}-V_{B D_{H}}
$$

and

$$
P W D_{H}=100 \frac{V_{W D_{H}}}{\operatorname{Var}(X)_{D_{H}}} .
$$

The other percentages in figure 5 are found similarly. 